\title{
Building Resilience: An Intervention to Enrich Positive Outcome in Personality Traits amongst Students Dorji Wangchuk
}

\author{
Khasadrapchu MSS, Ministry of Education, Thimphu, Bhutan \\ Received: 12 Apr 2021; Received in revised form: 19 May 2021; Accepted: 08 Jun 2021 \\ (C2021 The Author(s). Published by TheShillonga. This is an open access article under the CC BY license \\ (https://creativecommons.org/licenses/by/4.0/)
}

\begin{abstract}
The universal call for education in the 21st century gears towards cultivating personal traits of students who are resilient in navigating through life successfully. Thus, resilience building must be initiated in the learning institutions across the country for a better world. Resilience building enriches the personality traits and creates a wholesome individual who can in turn create a better world to be in. This study explored the impact of resilience building on academic performance and development of the personality traits in the young minds of Khasdrapchu MSS, Thimphu, based on five factor model of personality.
\end{abstract}

The sample students were selected using need assessment and screening tools. The vulnerable students were prioritized to be intervened with resilience building program. 37 students from classes VII to X were selected employing purposive sampling technique. The methodology incorporated was quantitative approach. The research design chosen was pretest and post-test.

In addition to a structured, self-administered questionnaire, the mid-term and annual examination results were included. Descriptive analysis was carried out to describe and summarize the raw data. Statistical techniques such as mean and standard deviation were used to infer correlation amongst the variables in the study.

The inferential statistics results indicated that there was a positive correlation between resilience building and personality traits. This was supported by an increase in mean and standard deviation in the posttest after the intervention was provided. The academic performance of the students heightened after the intervention. It can be concluded that building resilience in students have positive outcomes on their personality traits and as well on their academic performance. Thus, the learning institutions must consider resilience building programs as interventions to help young people navigate through life well.

Keywords - Intervention, Personality Development and Secondary School student, Resilience.

\section{INTRODUCTION}

The universal call for education in the $21 \mathrm{st}$ century embarks on teaching learners to understand that learning is a lifelong process and that one must be responsible to achieve moral courage, optimism, critical and creative thinking, integrity, self-reliance, patriotism, loyalty, self-respect, leadership of the self, discipline and resilience to become competent and good citizens. The whole teaching and learning process is geared towards cultivating personal traits of the students which assists them in navigating through life successfully.

However, students face adversities at some point in their educational career. These may include teasing and bullying, conflict with teachers or parents, competition or disagreements with peers, homework, tests and class presentations, and the transition from one school to another. There are personal crises, such as illness, loss of a loved one, abuse, financial instability, lack of parental guidance, shared reality of tragic events in the community, news, natural disasters, change in lifestyle, and adverse daily experiences.

The scenario at the national level is worrisome as Bhutan ranked 59 in the world in 2017, with suicide deaths at 12.16 per 100,000 of population. Bhutan's ranking has further dipped to 54 in 2018 according to World Population Review data, with suicide rate of 11.4 per 100,000 of population [5]. Furthermore, 10 students out of 48 cases in 2019 committed suicide which accounts to $20.83 \%$ [27]. Failures and disappointments in life are behind such unhealthy and destructive behaviours [3] In addition the researcher holds that such individuals 
are slower to recover from setbacks and may experience more psychological distress as a result.

The data denotes the need for an intervention in the schools to prohibit the loss of lives. Khasadrapchu MSS is no exception; it has witnessed students battling the challenges of life. Urban poverty, lack of parental care, domestic violence, low literacy rates of parents, dearth of emotional support and negligible family bonding has led to an increase in number of vulnerable students. In the words of Franklin Roosevelt, "We cannot always build the future for our youth, but we can build our youth for the future" (1940). Khasadrapchu MSS in its mission to prepare youths for an uncertain future incorporates building resilience as an antibody. The school aspired to provide the students genuine feelings of competence, belonging, usefulness, potency, and optimism through powerful, repeated, and authentic school experiences.

In response to the aforementioned problem, this study attempts to establish theory that relates building resilience as an intervention to develop personality traits in students which will enable them to cope with the challenging life experiences and stave off the potential negative psychological effects. This research would enrich the culture of building resilience amongst other Middle Secondary Schools. It would benefit the education system and society at large in conferring to building resilience in schools.

\subsection{Theoretical orientation of the problem}

Students face a wide array of barriers in their lives that not only jeopardize their performance in, and completion of, school but also jeopardize their physical health and psychological wellbeing in ways that can follow them into their adult lives [14].

There is emerging evidence that schools have the potential to influence positive children's bio-psychosocial growth and development. However, the identification of the protective factors which could be affected by school based interventions, the role schools can play in collaboration with children's families, communities, and other service providers, and to what extent interventions need to focus on changing children's school environments rather than changing children themselves must be taken into consideration [8]; [28].

\subsubsection{Concept of Resilience}

Indeed, this definition of resilience displays some consistency with the general definitions of resilience within the literature, which describe it as the capacity to achieve good outcomes, or to 'bounce back' from adverse factors [17]; [1]; [24], such as a lack of positive opportunities or difficult circumstances that may be caused by various mental, social, or physical deficits [10]. The importance of using correct terminology in regards to resilience has been outlined who have argued that the use of the term, especially when used in school-based resilience frameworks has tended to be conceptually weak and as a result determining whether a framework is actually resilience-based can prove difficult [9]. Resilience is primarily a phenomenon that has been studied in children and young people and has tended to focus on individuals who are at risk from mental health issues, rather than focusing on how resilience is used as a coping mechanism against daily setbacks. Although resilience has previously been argued as an individual personality trait that is dependent on innate characteristics, it is now widely regarded as an outcome of various environmental conditions and influences that are formed by the child's own experiences, relationships and opportunities [17]; [16]; [30] with such areas as the child's family, peer groups, schools and community playing key roles in the formation of resilience.

\subsubsection{Importance of Building Resilience}

Resilience involves more than continuing to persist despite difficulty: resilient students interpret academic or social challenges in a positive way. Resilience isn't a fixed trait. Flexibility, adaptability, and perseverance can help people tap into their resilience by changing certain thoughts and behaviors [11].

The importance of resilience in mental health is discussed as a life skill taken into adulthood [2]. He opines that more a resilient the person is, the lesser the chances of experiencing stress as they are equipped to deal with life's pressures. Research shows that students who believe that both intellectual abilities and social attributes can be developed show a lower stress response to adversity and improved performance.

Marilyn Price-Mitchell articulates, "children who develop resilience are better able to face disappointment, learn from failure, cope with loss and adapt to change. We recognize resilience in children when we observe their determination, grit, and perseverance to tackle problems and cope with the emotional challenges of school and life" [19].

Similarly, The Education Hub asserts that students with higher resilience tend to have more positive outcomes (including greater wellbeing) and exhibit fewer problem behaviours [25]. This is because resilient people display the courage and motivation to face problems and difficulties accurately (rather than denying or exaggerating them) and maintain a positive mindset and the confidence to persevere. 
1.1.3 Relationship between Resilience and Five Factor Model of Personality

The correlation between resilience and the personality development model is inevitable in the study in order to measure the effect of resilience building program in the school. A personality trait is a characteristic aspect of an individual's cognition, affect, or behavior that tends to be stable over time and consistent across relevant situations. The five-factor model of personality (FFM) is a set of five broad, bipolar trait dimensions, often referred to as the Big Five: Extraversion, Agreeableness, Conscientiousness, Neuroticism, and Openness to Experience. These five dimensions efficiently capture a wide range of individual differences in personality, and consequently the FFM is the most widely used structural model in personality measurement and research [22].

\subsubsection{Five Factor Model of Personality}

Each Big Five dimension is defined by a number of more-specific facet traits, and is manifested through a variety of behaviors [12]; [13]

Extraversion can be generally defined as the extent to which an individual is talkative and outgoing in social situations. Its core facets include sociability (vs. shyness), assertiveness (vs. submissiveness), and activity (vs. lack of energy). Behaviorally, extraverts tend to talk a lot, take charge in group situations, and express positive emotions, whereas introverts tend to feel uncomfortable in social situations, and keep their thoughts and feelings to themselves.

Agreeableness is an important aspect of social behavior. It concerns the extent to which someone behaves pro-socially toward others and maintains pleasant, harmonious interpersonal relations. Key facets of Agreeableness include compassion (vs. lack of concern for others), politeness (vs. antagonism), and trust (vs. suspicion of others). Those high in Agreeableness are more willing to help and forgive others, and treat others with respect; those low in Agreeableness tend to look down on others, start arguments, and hold grudges.

Conscientiousness describes an individual's capacity to organize things, complete tasks, and work toward long-term goals. Its key facets include orderliness (vs. disorganization), self-discipline (vs. inefficiency), and reliability (vs. inconsistency). Highly conscientious individuals prefer order and structure, are productive workers, tend to follow rules and norms, and are better able to delay gratification, whereas those low in Conscientiousness have difficulty controlling their impulses and are easily distracted from tasks.
Neuroticism (sometimes referred to by its socially desirable pole, Emotional Stability) concerns the extent to which someone is prone to experiencing negative emotions and moods. Its core facets include anxiety (vs. calmness), depression (vs. contentment), and emotional volatility (vs. stability). Highly neurotic individuals experience more frequent and intense negative emotions, such as fear, sadness, and frustration, and have frequent mood swings. Those low in Neuroticism remain calm and optimistic, even in difficult situations, and find it easier to regulate their emotions.

Openness to Experience refers to the overall depth and breadth of an individual's intellectual, artistic, and experiential life. Important facets of Openness include aesthetic sensitivity (vs. insensitivity), imagination (vs. lack of creativity), and intellect (vs. lack of intellectual curiosity). Highly open individuals tend to have a broad range of interests, and enjoy learning and trying new things; those low in Openness tend to have narrower interests, and prefer familiarity and routine over novelty and variety. However, there are fewer consensuses about the definition of Openness than about the other Big Five dimensions. Some researchers prefer the alternative label Intellect, and propose that intelligence should be included as an aspect of this dimension alongside intellectual curiosity and interests.

\subsubsection{Prediction of Life Outcomes with Big Five}

Big Five has been shown to predict a number of important life outcomes [18]; [22], as discussed below:

Extraversion positively predicts interpersonal outcomes such as peer acceptance and friendship, social status, number of dating partners, and relationship satisfaction. Extraverts tend to prefer and perform better in social and enterprising occupations; they are also more likely than introverts to assume leadership positions in their workplaces and communities. Psychologically, extraverts tend to have higher self-esteem and greater subjective well-being, especially more frequent and intense positive affect; compared with introverts, they also show greater emotional resilience and better coping skills in response to negative events.

Agreeableness is an important predictor of social outcomes. Agreeable individuals tend to be accepted and well-liked by their peers, and experience greater dating and relationship satisfaction, whereas those low in Agreeableness are more likely to experience peer rejection and bullying. Agreeable individuals tend to seek out and succeed in social occupations and collaborative work environments. They also tend to be more religious, are more likely to volunteer and assume community leadership positions, and are less likely to engage in criminal 
behavior. Low Agreeableness is associated with health risks such as heart disease and decreased longevity.

Conscientiousness is the strongest predictor of overall academic and occupational success. In general, conscientious students earn higher grades and conscientious employees perform better in a variety of jobs, whereas individuals low in Conscientiousness are more likely to engage in counterproductive work behaviors. Conscientiousness is also an important, positive predictor of physical health, mental health (including selfesteem and subjective well-being), and longevity. The associations of high Conscientiousness with overall health extend to many specific health-related behaviors, including a healthier diet, more frequent exercise, less frequent tobacco, alcohol, and drug use, and less risky sexual behavior. Conscientious individuals are also more likely to be religious and hold conservative political attitudes, and less likely to engage in antisocial and criminal behavior.

Neuroticism is a strong, negative predictor of subjective well-being: highly neurotic individuals tend to experience greater negative affect and less satisfaction with life, as well as lower self-esteem. This general unhappiness extends to more-specific life domains. For example, neurotic individuals tend to feel less secure and satisfied about their family, peer, and romantic relationships, and are at greater risk for relationship conflict, abuse, and divorce. They also tend to be less satisfied with, committed to, and successful in their jobs. Because neurotic individuals tend to experience frequent and intense negative emotions, and have difficulty coping with negative events, they are at increased risk for mental illness, especially clinical depression and anxiety disorders.

Openness to Experience is an important predictor of intellectual outcomes. Highly open individuals tend to perform better on tests of intelligence and creativity, and complete more years of formal education. They are especially likely to pursue and succeed in artistic, scientific, and technical careers. Compared with their less open peers, they are also more likely to engage in drug use, to describe themselves as spiritual (but not necessarily religious), and to hold liberal political and social attitudes.

\subsection{Operational definition of the terms}

The key areas of the study are Resilience, Intervention, Personality Development and Secondary School students.

\subsubsection{Resilience}

The ability of an individual to recover quickly from difficulties or adversities in life

\subsubsection{Intervention}

It is the process of taking action on the strategies and activities that have been planned during the planning stage of the first cycle. Intervention is also called the implementation of the activities as agreed upon by the various groups involved in the action research.

\subsubsection{Personality Traits}

Personality traits reflect people's characteristic patterns of thoughts, feelings, and behaviors. Personality traits imply consistency and stability-someone who scores high on a specific trait like Extraversion is expected to be sociable in different situations and over time.

\subsubsection{Students}

It refers to the vulnerable students of Khasadrapchu Middle Secondary School who participated in the intervention program of building resilience.

\subsection{Research objectives}

The study attempts to achieve the following objectives.

- To determine the effectiveness of the resilience building program as an intervention in enriching personality traits amongst students.

- $\quad$ To measure the changes in the personality traits of the students before and after the intervention using pretest and posttest quasi-experimental design.

- To study the reliability of Five-Factor Model Personality as a tool in measuring the outcome of resilience.

- $\quad$ To study the impact of building resilience on the academic performance of the students.

\subsection{Hypotheses}

The hypotheses stated below were verified to achieve the objectives:

- $\quad$ There is a positive correlation between resilience and academic performance.

- There is a significant difference in the mean marks of students before and after the intervention.

- $\quad$ There is a positive correlation between the fivefactor Model personality and the impact of resilience.

\subsection{Delimitation of the study}

The study was delimited as below:

- Khasadrapchu Middle Secondary School of Thimphu, Bhutan, was selected for the data collection. 
- Only the vulnerable students through need assessment and screening procedures were selected as sample for the data collection and received the intervention program.

- $\quad 37$ students from classes VII to X were selected for the study in accordance with their vulnerable status and need for intervention program.

\section{METHODOLOGY}

Research methodology is the specific procedures or techniques used to identify, select, process, and analyze information about a topic. In a research paper, the methodology section allows the reader to critically evaluate a study's overall validity and reliability. The methodology section answers two main questions: How was the data collected or generated? How was it analyzed? [29]. It is significant to select appropriate tools, methods and designs of research, the sampling method and the statistical techniques according to the problem one is working on. Thus, this section discusses about these various techniques of methods for the research.

\subsection{Research Method}

Using a quantitative approach, the present study has been conducted based on a correlational descriptive study using surveying method. The correlational model aims to present the relationships existing between two or multiple variables without interference. More detailed information can be obtained regarding the relationships between the variables by using various different techniques should the need arise [4]. The relationship between resilience and the five factor personality traits are correlated in the study.

\subsection{Research Design}

The research design adapted for the study is pretest posttest design. It is an experiment where measurements are taken both before and after a treatment. The design enables one to see the effects of some type of treatment on a group. Pretest posttest designs may be quasi-experimental, which means that participants are not assigned randomly. This research design can account for incremental progress shown by students attending the intervention program.

According to Dimitrov and Rumrill, Pretestposttest designs are widely used in behavioral research, primarily for the purpose of comparing or measuring change resulting from experimental treatments [6]. In this research, change is commonly measured in dependent variables under Five Factor Model such as Extraversion, Agreeableness, Conscientiousness, Neuroticism, and Openness to Experience. The measurement of change provides a vehicle for assessing the impact of the intervention in enhancing the Five Factor Model of Personality in students and as well as evaluating the effectiveness of the School Resilience Development Program as an intervention strategy to build resilience at Khasadrapchu MSS.

\subsection{Sampling Technique}

In research terms a sample is a group of people, objects, or items that are taken from a larger population for measurement. The sample should be representative of the population to ensure that we can generalise the findings from the research sample to the population as a whole [29]. The preferred sampling technique which suited the study was purposive sampling. It is also known as judgment, selective or subjective sampling in which researcher relies on his or her own judgment when choosing members of population to participate in the study [20]. The samples for the study were selected after carrying out using need assessment tools. Then the class teachers of Khasadrapchu MSS conducted the screening process to identify vulnerable students who needed the timely intervention of resilience building program. 37 students were selected of which 12 were in grade $\mathrm{X}, 11$ samples in grade IX, four samples in class VIII and 10 samples in Class VII. Only the samples under study received the treatment included in the intervention program for building resilience.

\subsection{Tools for data collection}

The data is collected from the sample using a survey questionnaire to gather information on the impact of building resilience on the students based on the five factor model of personality. The questionnaire was constructed with 40 items which catered to all the personality traits stated in the five factor model of personality based on 5point Likert Scale [29] is a type of psychometric response scale in which responders specify their level of agreement to a statement typically in five points: (1) Strongly disagree; (2) Disagree; (3) Neither agree nor disagree; (4) Agree; (5) Strongly agree.

The correlation of resilience building and its impact after the intervention program was based on the five factor model of personality traits. The positive outcome of the resilience building program was correlated with the academic performance of the students in the MidTerm Examinations which inferred the outcome before the intervention and the outcome after the intervention was reflected from the Annual Examination performance of the students under study. 


\subsubsection{Reliability and Validity}

The technique of data triangulation was used in the study. Triangulation is the use of multiple sources of data for bringing different kinds of evidence into some relationship with each other so that they can be compared and contrasted for validity and objectivity of the study [7]. Pre-data and post-data are used in the triangulation process.

In the realm of research design pretest-posttest designs is the preferred method to compare participant groups and measure the degree of change occurring as a result of treatments or interventions. Statistical analysis can then determine if the intervention had a significant effect.

Measures of the Big Five have shown considerable reliability and inter-rater agreement, and can be used to predict a variety of important social, occupational, psychological, and health outcomes. These five dimensions efficiently capture a wide range of individual differences in personality, and consequently the Five Factor Model is the most widely used structural model in personality measurement and research [22].

\subsection{Data collection and Procedure}

The data on the impact of resilience program based on the five factor model of personality were collected using the self-constructed questionnaire. Midterm and Annual examination results of the samples under study were taken to correlate resilience building and academic performance. The questionnaires were administered to 37 identified samples and collected by the facilitators engaged in School resilience Development Program.

During the collection of data, the objectives and instructions of the data were informed to the students and the maintaining of data confidentiality was ensured to them. Thus, the data collected were then tabulated and statistically tested using the technique mentioned below.

\subsection{Statistical Technique}

The data collected were tabulated, and analyzed using the SPSS version 22 statistical package for windows. Following techniques of analysis were employed for further interpretation:

- Statistical techniques Mean: .The first method that's used to perform the statistical analysis is mean, which is more commonly referred to as the average.

- Standard Deviation: Standard deviation is a method of statistical analysis that measures the spread of data around the mean. Standard deviation is mainly used when you need to determine the dispersion of data points.

- Correlational Descriptive Technique: Descriptive, correlational, and experimental research tools are used to collect and analyze data. Descriptive designs are efficient in analyzing data collected from surveys. Correlational research tools measure two or more relevant variables and assess a relationship between or among them.

\subsection{Intervention}

The intervention for the study was the School Resilience Development Program. Dzongkhag Education Sector, Thimphu Dzongkhag deemed it necessary for the Middle Secondary Schools to build resilience amongst the young people in the school. Khasadrapchu MSS focused on the needy and vulnerable students. Task force members which consisted of five teachers from each school including the Principal were trained to roll out the program in September 2019. The intervention duration was for three months until the end of November 2019.

The activities included in the intervention were:

- Brain Science inclusive of neuroplasticity, brainamygdala, prefrontal cortex, flight-fight-freeze response)

- $\quad$ Effects of Breathing (Why focus on breathing?)

- Benefits of Mindfulness Practices

- Dedicated and Short Micro Practices of Mindfulness

- Introduction of Six Vital Positions

- Familarize with the Process and Cycle of Mindfulness

- $\quad$ Experiences and Thought Sharing

- $\quad$ Emotional Awareness

- Introduction to the Idea of Emotional Wheel

- Body Reactions to Different Emotions

- Head, Body and Heart Check In and Body Scan

- Introduction to ABCD Model.

\section{ANALYSIS AND INTERPRETATION}

The outcome of resilience building is studied based on the five factor model of personality which is a set of five broad, bipolar trait dimensions, often referred to as the Big Five: Extraversion, Agreeableness, Conscientiousness, Neuroticism, and Openness to Experience. Furthermore, the study will interpret the outcome of resilience building on the academic performance of the students. 
3.1 Results pertaining to the correlation between resilience building and big five in the pretest.

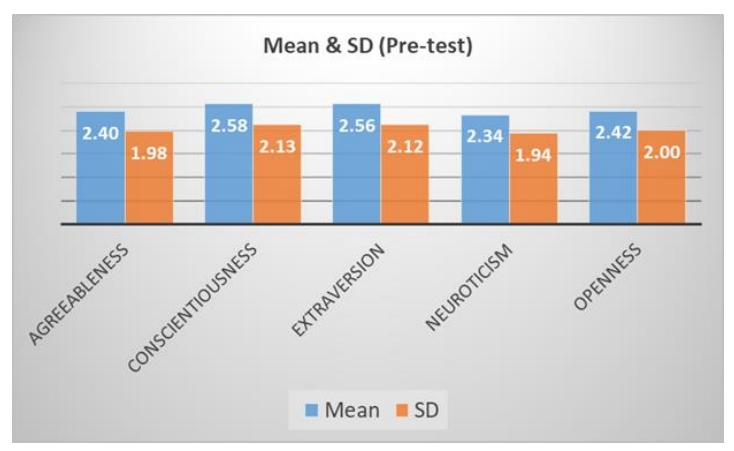

Fig.1: Pretest result on five factor model of personality

Fig. 1 depicts the pretest result on the five different personality traits. The agreeableness trait had 2.4 as its mean and 1.98 as its standard deviation. There was 2.58 and 2.13 as the mean and standard deviation respectively for conscientiousness trait. The personality trait of extraversion saw a mean of 2.56 and a standard deviation of 2.12. Neuroticism trait had scored a mean of 2.34 and its standard deviation was 1.94 . The fifth factor in the model of personality which is openness to experience marked a mean of 2.42 and a standard deviation of 2 .

\subsection{Results pertaining to the correlation between} resilience building and big five in the posttest

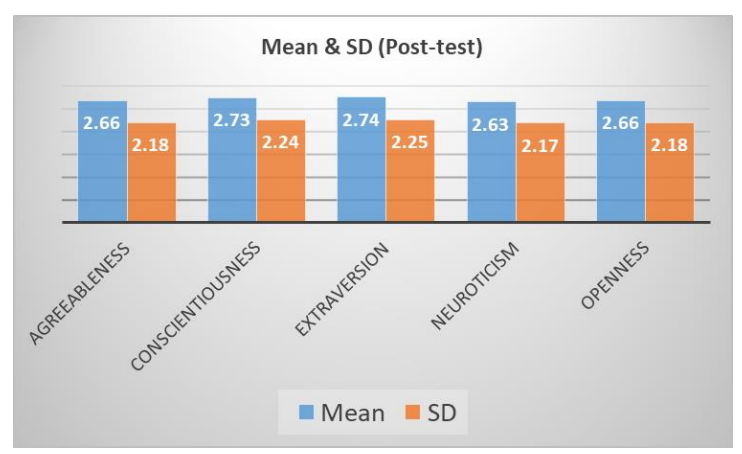

Fig.2: Posttest result on five factor model of personality

Fig. 2 depicts the posttest result on the five different personality traits. The agreeableness trait had 2.66 as its mean and 2.18 as its standard deviation. There was 2.73 and 2.24 as the mean and standard deviation respectively for conscientiousness trait. The personality trait of extraversion saw a mean of 2.74 and a standard deviation of 2.25. Neuroticism trait had scored a mean of 2.63 and its standard deviation was 2.17 . The fifth factor in the model of personality which is openness to experience marked a mean of 2.66 and a standard deviation of 2.18 .
3.3 Results pertaining to the differences in mean amongst the personality traits before and after the intervention

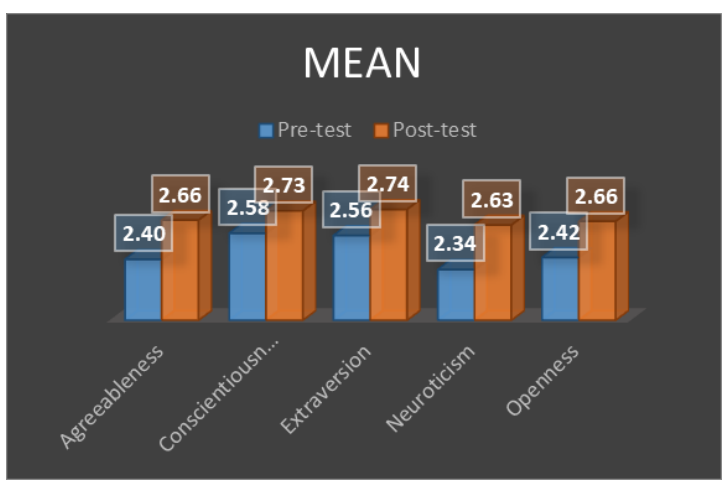

Fig.3: Differences in mean for pretest and posttest

Fig. 3 illustrates the comparative analysis of the mean in the various personality traits in pretest and posttest. In the first trait agreeableness the mean increased from 2.4 in the pretest to 2.66 in the pretest marking a positive difference of 0.26 . Similarly, in conscientiousness there was an increase of 0.15 in its mean. Comparing the mean scored in the extraversion personality trait there was an increase of 0.18 . In the aspect of neuroticism the mean increased in the posttest with a positive increase of 0.29. Openness to experience saw an increase of 0.24 in its mean.

3.4 Results pertaining to the differences in standard deviation amongst the personality traits before and after the intervention.

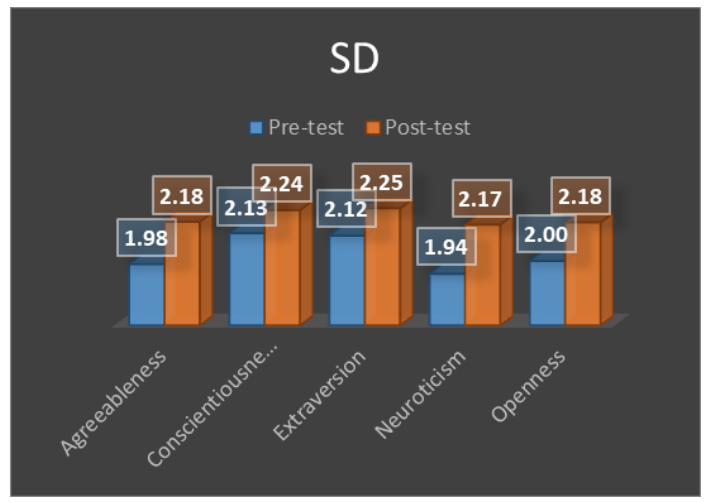

Fig.4: Differences in standard deviation for pretest and posttest

Fig. 4 illustrates the comparative analysis of the standard deviation in the various personality traits in pretest and posttest. In the first trait agreeableness the standard deviation increased from 1.98 in the pretest to 2.18 in the pretest marking a positive difference of 0.2. Similarly, in conscientiousness there was an increase of 0.11 in its standard deviation. Comparing the standard 
deviation in the extraversion personality trait there was an increase of 0.13 . In the aspect of neuroticism the standard deviation increased in the posttest with a positive increase of 0.23 . Openness to experience saw an increase of 0.18 in its standard deviation.

\subsection{Results pertaining to the impact of resilience building in academic performance of the students}

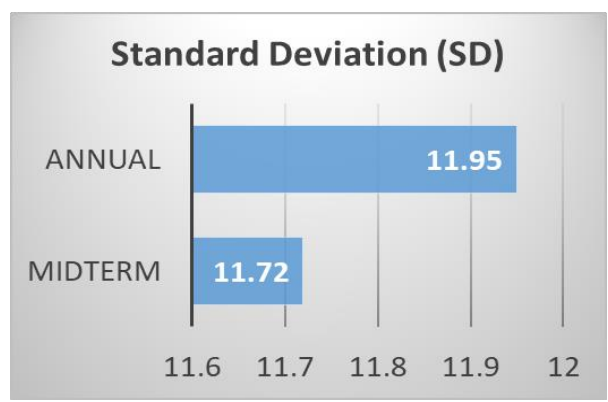

Fig. 5: Differences in the academic performance of the students

The marks of the 37 student participants were computed for both the examinations and the average mean calculated. It must be noted that the mid-term is the academic performance of the students before the intervention and annual examination mean marks reveal the academic performance by the students after the intervention. Positive correlation between resilience building, development of personality trait and their academic performance was found. The result showed an increase of 2.49 in the mean marks.

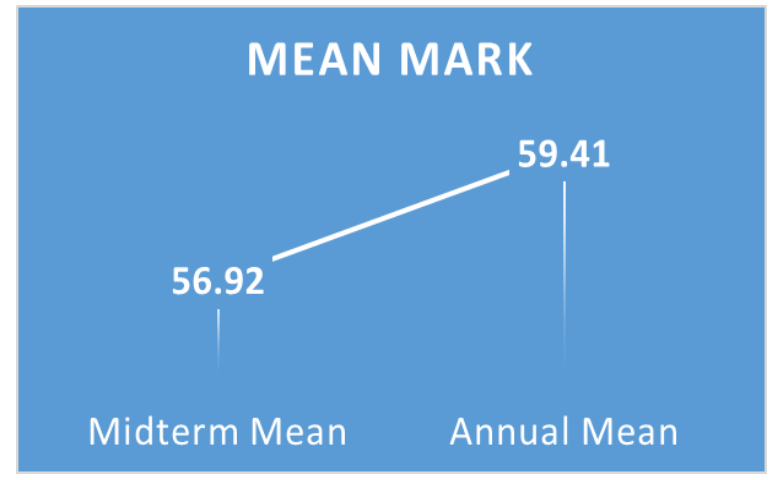

Fig.6: Differences in standard deviation for Annual and Mid-term examination

Fig. 6 shows the differences in the standard deviation of annual and mid-term examination. The standard deviation of midterm examination was 11.72 and the standard deviation of annual examination increased to 11.95. There was a positive increase of 0.23 .

\section{CONCLUSION, RECOMMENDATIONS AND SUGGESTIONS}

\subsection{Conclusions}

The main aim of the study was to examine the impact of building resilience on enriching personality traits in students. Furthermore, the study also encompassed the relationship between building resilience and its impact on academic performance. The investigator used quantitative descriptive survey method for the overall research. A selfconstructed tool in the form of questionnaire was administered to the sample to compute the effectiveness of the intervention.

The data was analyzed using SPSS version 22, in which statistical techniques like mean and standard deviation were used to find the differences and relationship between the variables. After the analysis, the results were interpreted.

The interpretations of the data lead to the conclusion, in which the important findings from the research are summed up. The conclusion further brings about recommendation for future researches and for reforms required for the system. Thus, the interpreted data led to the following conclusions of the findings and recommendations were also made.

\subsubsection{There is a positive correlation between resilience} and academic performance.

The study revealed a positive correlation between building resilience and academic performance. The mean marks of the students in the annual exam were much higher as compared to the midterm before the intervention. It can be deduced that building resilience in students can enhance better performance of the students in the academic arena.

4.1.2 There is a significant difference in the mean marks of students before and after the intervention.

The hypothesis was validated by the computation of the mean marks in the midterm and annual examination. The mean marks of the students soared higher in the annual exam after the intervention of school resilience development program at Khasadrapchu MSS.

4.1.3 There is a positive correlation between the fivefactor Model personality and the impact of resilience.

The positive correlation between the intervention of resilience building and the five factor model personality is validated by the score in its mean and standard deviation. The data analysis show an increase in the posttest after the intervention was provided in all the 
personality traits such as agreeableness, conscientiousness, extraversion, neuroticism and openness to experience.

\subsection{Limitations}

Some limitations of the study are as follows:

- The area of the study was limited to only one school.

- $\quad$ The sample size was small; i.e. 37 secondary school students.

- $\quad$ The tool used was self-constructed which may compromise on the reliability and validity of the test.

- The study can stretch out to government and private schools as well as rural and urban schools.

\subsection{Suggestions}

Following suggestions can be taken up by other investigators for similar study:

- Similar study can be carried out in government and private schools.

- It can be carried out in rural and urban schools too.

- $\quad$ The study of similar nature can be carried out in primary and higher level of schools as well.

- $\quad$ The study can be done in national level by taking up different schools in various districts.

- Larger sample size can be used for higher reliability and validity.

\subsection{Recommendations}

Following are some recommendations after the findings of the study:

- $\quad$ Building resilience in students has positive impact on their academic performance. Therefore the teachers must strive to build resilience in children.

- Building resilience in students has positive outcome on students' personality development. Therefore, educators must develop programs on resilience to enrich the personality traits of children.

- Students must be given a thorough orientation regarding the importance of inculcating resilience.

- An intervention such as building resilience is effective. Thus, it could be applied in the school curriculum.

\section{ACKNOWLEDGEMENTS}

I am honoured that Dr. Ganeshman Gurung, Officiating Dean of Research and Industrial Linkage, Samtse College of Education has been gracious enough to review this study. Without his guidance and feedback this research study would not have been standardized. I remain indebted for life.

I cannot express enough gratitude to my mentors Chief Dzongkhag Education Officer Mr. Tashi Namgyel and Deputy Chief Education Officer Mrs. Lham Tshering for their guidance and far sighted leadership. It was their initiative of building resilience in schools. I am fortunate to have a vibrant task force for their continued support and encouragement: Mrs. Tshering Om S, Ms. Tenzin Zangmo, Ms. Tashi Yangzom, and Mr. Lhendup Dorji. I offer my sincere appreciation for the learning opportunities provided by my Education fraternity. I have been engaged in the life long process due to the expectation I see in the eyes of my innocent students. Completion of the research project would not be possible without the cooperation and consent of my students who were gracious enough to be included in the study.

Completion of this project could not have been accomplished without the support of my young colleague Mr. Ugyen Dendup. He has rendered his technical expertise in statistical analysis. I am grateful for your kind assistance. Heartfelt gratitude goes out to my parents and siblings for their continued support and encouragement. You have taught me humanity and compassion which enables me to learn more for a better world. I am indeed indebted for all the contributions made by the members of my Khasdrapchu MSS family. The countless times you kept the school children our priority during our hectic schedules will not be forgotten.

Thank you my sweet heart grandson Jigme Yoedsel Namgyel for keeping me awake and encouraging me to learn more. You inspired me to strive harder to keep up with the changing world and live up to the expectations of the smart new generation. Finally, to my caring, loving, and supportive wife, Ugyen Chozom: my deepest gratitude. Your encouragement when the times got rough are much appreciated and duly noted. It was a great comfort and relief to know that you were willing to provide management of our household activities while I completed my work. Accept my heartfelt wishes of wellbeing to all.

\section{REFERENCES}

[1] [1] Bonanno, G., Brewin, C., Kaniasty, K., \& La Greca, A. (2010). Weighing the Costs of Disaster: Consequences, Risks, and Resilience in Individuals, Families, and 
Communities. Psychological Science in the Public Interest , 11(1), 1-49.

[2] [2] Bobberman, J. (2018). Why building resilience in children is important? Retrieved from.https://teamkids.com.au/why-building-resilience-inchildren-is-important/

[3] [3] Cherry, K. (2021). What is Resilience? Retrieved from. https://www.verywellmind.com/what-is-resilience-2795059

[4] [4] Cresswell, J. W. (2009). Research design: Qualitative, quantitative, and mixed methods approaches. Los Angeles: Sage Publications.

[5] [5] Dem, P. (January,8th 2019). Suicide cases, still a concern. Business Bhutan. Retrieved from. https://businessbhutan.bt/2019/01/08/suicide-cases-still-aconcern/

[6] [6] Dimitrov, D, M. \& Rumrill (Jr), P, D. (2003). PretestPosttest designs and Measurement of Change. Retrieved from.https://www.researchgate.net/publication/10826237_P retest Posttest_Designs_and_Measurement_of_Change

[7] [7] Elliott, J. \& Partington, D. (1975). Three Points of View in the Classroom: Generating Hypotheses from Classroom Observations, Recordings and Interviews. (Norwich: Centre for Applied Research in Education).

[8] [8] France, A., Bottrell, D., \& Armstrong, D. (2012). A political ecology of youth and crime. London, UK: Palgrave MacMillan. http://dx.doi.org/10.1057/9781137291486

[9] [9] Hart, A., \& Heaver, B. (2013). Evaluating resiliencebased programs for schools using a systematic consultative review. Journal of Child and Youth Development , 1(1), 27- 53.

[10] [10] Hidon, Z., Smith, G., Netuveli, G., \& Blane, D. (2008). Understanding adversity and resilience at older ages. Sociology of Health and Illness, 30(5), 726-740.

[11] [11] Hurley,K. (2020). What Is Resilience? Your Guide to Facing Life's Challenges, Adversities, and Crises. Retrieved from. https://www.everydayhealth.com/wellness/resilience/

[12] [12] John, O. P., Naumann, L. P., \& Soto, C. J. (2008). Paradigm shift to the integrative Big Five trait taxonomy: History, measurement, and conceptual issues. In O. P. John, R. W. Robins, \& L. A. Pervin (Eds.), Handbook of personality: Theory and research (p. 114-158). The Guilford Press.

[13] [13] Leary, M. R., \& Hoyle, R. H. (Eds.). (2009). Handbook of individual differences in social behavior. The Guilford Press.

[14] [14] Mallin, B., Walker, J. R., \& Levin, B. (2013). Mental health promotion in the schools: Supporting resilience in children and youth. In S. Prince-Embury, \& D. H. Saklofske (Eds.), Resilience in Children, Adolescents, and Adults (pp. 91-112). New York: Springer. http://dx.doi.org/10.1007/978-1-4614-4939-3_7

[15] [15] Masten, A. (2001). Ordinary Magic: Resilience Processes in Development. American Psychologist, 56(3), 227-238.

[16] [16] Masten A. S., Coatsworth J. D. (1998). The development of competence in favorable and unfavorable environments: Lessons from research on successful children. American Psychologist, 53, 205-220.

[17] [17] Masten A. S., Garmezy N. (1985) Risk, vulnerability, and protective factors in developmental psychopathology. In: Lahey B, Kazdin A, editors. Advances in clinical child psychology, 8, 1-52.

[18] [18] Ozer, D. \& Benet, V.(2006). Personality and the Prediction of Consequential Outcomes. Annual Review of Psychology 57(1): 401-21.

[19] [19] Price-Mitchell, M.(2015). Does Your Classroom Cultivate Student Resilience?Retrieved from https://www.edutopia.org/blog/8-pathways-cultivatestudent-resilience-marilyn-price-mitchell

[20] [20] Saunders, M., Lewis, P. \& Thornhill, A. (2012). Research Methods for Business Students (6th ed.), Pearson Education Limited p. 288

[21] [21] Schoon, I., and Bartley, M. (2008). The role of human capability and resilience. The Psychologist, 21(1) , 24-27.

[22] [22] Soto, C. J., Kronauer, A., \& Liang, J. K. (2016). FiveFactor Model of Personality. In S. K. Whitbourne (Ed.), Encyclopedia of adulthood and aging , 2, 506-510. Hoboken, NJ: Wiley.

[23] [23] Springer Science. (2010). 5-Point Likert Scale. Retrieved from. https://link.springer.com/referenceworkentry/10.1007\%2F9 78-0-387-78665-0_6363

[24] [24] Tedeschi, R. G., \& Calhoun, L. G. (1995). Trauma \& transformation: Growing in the aftermath of suffering. Thousand Oaks, CA: Sage Publications.

[25] [25] The Education Hub. (2020). An Introduction to Resilience in Educational Settings. Retrieved from. https://theeducationhub.org.nz/an-introduction-toresilience-in-educational-settings/\#wpcf7-f39039-p30351o2

[26] [26] The Hillingdon Hospital.(2006). Sampling In Research. $\quad$ Retrieved from. https://www.thh.nhs.uk/documents/_Departments/Research /InfoSheets/16_sampling_research.pdf

[27] [27] Tshomo, D. (2019). Seven suicide cases reported every month in 2018. Kuensel. Retrieved from. https://kuenselonline.com/seven-suicide-cases-reportedevery-month-in-2018/

[28] [28] Ungar, M., \& Liebenberg, L. (2013). Ethnocultural factors, resilience, and school engagement. School Psychology International, 34(5), 514-526. http://dx.doi.org/10.1177/0143034312472761

[29] [29] University of Witwatersrand. (2020). Research Support: Research Methodology. Retrieved from. https://libguides. wits.ac.za/c.php?g=693518\&p=4914913

[30] [30] Werner, E. E., \& Smith, R.S. (1992). Overcoming the odds: High-risk children from birth to adulthood. Ithaca, NY: Cornell University Press. 